\title{
Edifícios públicos. Arquitetura forense: arquitetura moderna questionando a simbologia e mitos do Poder Judiciário no Estado de São Paulo
}

\begin{abstract}
Resumo
No estado de São Paulo, os edifícios do Judiciário, assim como os demais edifícios públicos, até fins dos anos 1950 eram projetados pelo Departamento de Obras Pública (DOP). Os edifícios da Justiça possuíam uma linguagem eclética, com forte ascendência acadêmica, que acentuava a presença do Estado e reforçava a hierarquia social. Com a introdução de um plano de governo com ideais modernizadores - o Plano de Ação (PAGE), de Carvalho Pinto (1959-1963) -, jovens arquitetos encontram solo para cultivar seus ideais de uma nova arquitetura, em que os edifícios forenses eram reformulados associando novas formas de relações sociais e de espaços democráticos, ainda que compatibilizados com as expectativas do "Estado modernizador" e "anos de euforia". Nesse período, a arquitetura no país viveu um momento singular de produção, além de contribuir para a difusão da arquitetura moderna.
\end{abstract}

Palavras-chave: edifícios públicos, plano de ação PAGE, arquitetura forense. s edifícios do judiciário no Estado de São Paulo até fins dos anos 1950 eram projetados pelo Departamento de Obras Pública (DOP), ${ }^{1}$ que contava no seu corpo técnico com um significativo número de engenheiros e arquitetos. Este corpo técnico estabeleceu ao longo da primeira metade do século XX a padronização como orientação projetiva para a construção, não apenas dos edifícios do judiciário, mas do conjunto dos edifícios públicos. Tal procedimento era defendido pelos técnicos do DOP como o mais viável e adequado para construir, rapidamente e com baixo custo, os diversos equipamentos públicos pelo interior do Estado e na capital, tais como: Escolas, Unidades de Saúde, Casas da Lavoura e Fóruns que possuíam modelos com variações dimensionais (até quatro disposições), para atender as capacidades necessárias do equipamento no município. Os projetos eram implantados sem levar em conta as condições físicas e espaciais dos terrenos (disposição e orientação do lote).

\author{
Maria Tereza R. Leme de Barros Cordido \\ Arquiteta e urbanista, doutoranda pelo Departamento de Arqui- \\ tetura e Urbanismo da Escola de Engenharia de São Carlos, \\ Avenida Trabalhador Sancarlense, 400, CEP 13566-590, São \\ Carlos, SP, (16) 3373-9294, terecordido@terra.com.br
}

Os edifícios da Justiça desenvolvidos pelo DOP possuíam uma linguagem eclética, com forte ascendência acadêmica. A simbologia do corpo da edificação, organizado simetricamente pelo eixo axial, ao mesmo tempo, sóbria e imponente, buscava representar o Poder Judiciário, de forma a acentuar a presença do Estado, mas, também, reforçando a hierarquia social. ${ }^{2}$

Nestes edifícios forenses podem-se identificar elementos como, simulacros de colunas e colunatas "neoclássicas", inscrições românicas e por vezes frontões nas fachadas. A hierarquia social e os valores da magistratura manifestavam-se, também, no agenciamento espacial. Ainda que pudesse estar subentendida uma questão funcional, a locação das funções na edificação não tinha como viés principal esta questão. No andar superior estão rigorosamente localizadas as funções estritas da justiça, tais como sala e gabinete do juiz e o grande 

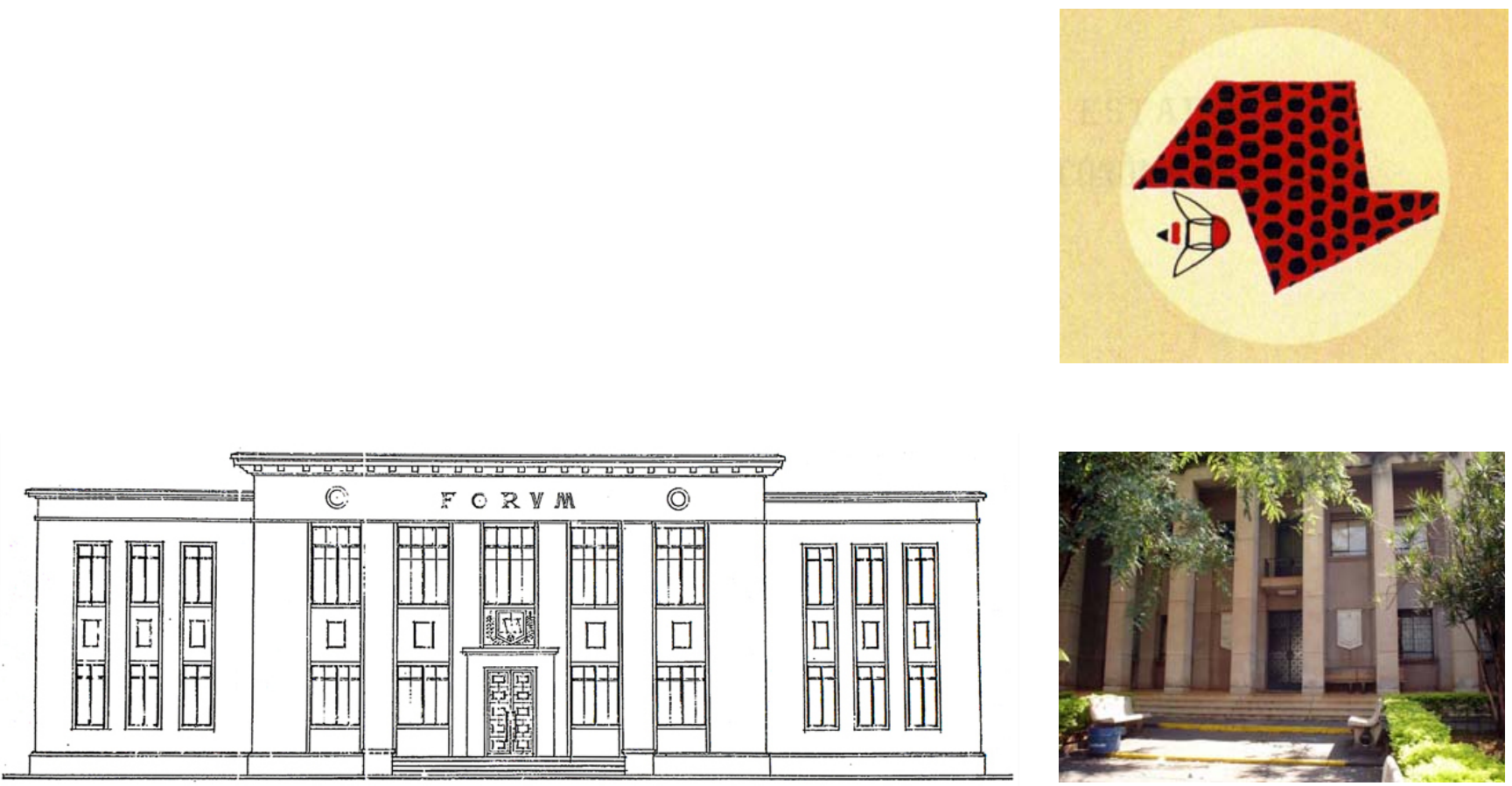

Figura 1: Símbolo do Plano de Ação. Fonte: Plano de Ação do Governo, São Paulo: Imprensa Oficial, 1959.

Figura 2: Fórum de Barretos elaborado pelo DOP. Fontes: Arquivo-morto do CPOS; fotografia de Leonardo Votta, 2006.

(1987/1991), através da Lei Estadual $n^{\circ} 7.394$ de 8/7/ 1991 que autoriza a transformação do Departamento de Edifícios e Obras Públicas DOP na empresa Companhia Paulista de Obras e Serviços - CPOS e a dissolução da CONESP. O DOP foi responsável pela produção de diversos edifícios públicos do Estado e desde a sua formação, foi se estruturando através da capacitação do aparelho do Estado, com a contratação de novos profissionais que contribuíram para a evolução do saber técnico, criando normas projetuais e construtivas.

2 Os projetos-padrão de Fóruns estavam divididos em quatro categorias: padrão $A$, $B, C$ e $D$, divisões as quais obedeciam a capacidade de acomodação dos números de cartórios e varas no edifício. salão do júri, estes com acabamentos internos de composição refinada, geralmente em madeira e tendo suas aberturas vedadas por grandes vitrais. No andar inferior localizam-se os serviços de acesso menos restrito, tais como cartórios de registros, varas e arquivos.

Embora a idéia de padronização destes Fóruns de Justiça pudesse ser aproximada à concepção racionalista de produção estandardizada, não há registros seguros que na construção dos mesmos houvesse de fato ganhos de economia, certamente, havia alguma noção de racionalidade, mas essa ocorria de forma avulsa, desintegrada de uma concepção sistêmica. A ausência de registros de processos de obra rotineiros indica que cada obra, tinha construção própria, independente do "caráter padrão" do projeto. Isso, aliado a permanência de ornamentos e de acabamentos, praticamente, artesanais, indica uma uniformização, no âmbito da peça de projeto, não inserida em uma seqüência de ações que justificasse plenamente a sua adoção. Exemplo disso é que a concepção construtiva, não previa a acomodação dos edifícios às variações de modelagem dos terrenos, o que tornava sua implantação, por vezes, imprópria.

O DOP manteve seus edifícios, com soluções ecléticas, impermeáveis à nova arquitetura até os finais dos anos 1950. Entretanto, os problemas surgidos que questionavam a própria funcionalidade deste modelo de produção, tais como a inadequação em relação aos terrenos, restrita possibilidade de ampliação, entre outros, associado à afirmação da arquitetura moderna brasileira criaram solo para que a produção, ainda sob a égide do Estado, fosse elaborada com profissionais de fora de seu quadro funcional, que sem as limitações imposta, ou assumidas, pelos arquitetos do quadro de servidores do Estado, puderam renovar a linguagem dos edifícios do Judiciário propugnando novos objetivos.

Desta forma, viabilizadas pelo Plano de Ação do Governo Carvalho Pinto (1959/1963) e contrapondo as inadequações da produção de edifícios públicos e seus valores, até então vigentes, as formulações modernas constituíram-se em um processo germinal de renovação na de equipamentos públicos. ${ }^{3}$ Os 
${ }^{3}$ O Plano de Ação do Governo do Estado, mais conhecido como PAGE ou Plano de Ação foi proposto em 1959, pelo Governo Carvalho Pinto (1959/1963), inspirado nas concepções do Movimento Economia e Humanismo fundado pelo Padre Lebret conformou-se como um plano desenvolvimentista com ações coordenadas para todas as secretarias do Estado. Com a orientação de Plínio de Arruda Sampaio, Carvalho Pinto convocou um grupo de especialistas para formar o "Grupo de Planejamento", encarregado de detalhar as diretrizes do Plano de governo. O PAGE ocorreu tendo como pano de fundo a política desenvolvimentista patrocinada pelo Plano de Metas no âmbito federal. Há em todo o Plano uma necessidade de "conciliar" o desenvolvimento industrial com o "interior agrário" e benefícios sociais. O que, de certa forma, refletia os compromissos com segmentos "distintos" das elites e a necessidade de compensar o discurso populista, do qual o Partido Democrata-Cristão-PDC - de Carvalho Pinto participava de forma problemática, apoiando Jânio Quadros no plano Federal (Carvalho Pinto participara do governo estadual anterior de Jânio), e no quadro estadual disputando a hegemonia com Adhemar de Barros (fundador do PSPPartido Social Progressista).

Além de seu coordenador Sampaio, faziam parte do Grupo de Planejamento do PAGE: Diogo Adolpho Nunes Gaspar, economista e Secretário Executivo; Celeste Ângela de Souza de Andrade, Diretora do Departamento de Estatística; Paulo Menezes Mendes da Rocha, Professor Catedrático da Escola Politécnica da USP; Ruy Aguiar da Silva Leme, Professor Catedrático da Escola Politécnica da USP; Antônio Delphim Netto, Assistente da Faculdade de Ciências Econômicas e Administrativas da USP: Sebastião Advíncula da Cunha, do Departamento Econômico do B.N.D.E.; Orestes Gonçalves, Chefe do Gabinete dos Estudos Econômicos e Financeiros da Secretaria da Fazenda e Ruy Miller Paiva, Engenheiro Agrônomo do Departamento da Produção Vegetal da Secretaria da Agricultura. arquitetos - profissionais liberais - aderentes às novas possibilidades que a arquitetura moderna estimulava, ante esta produção questionaram as fórmulas e concepções de longa data adotadas, configuradas pelos projetos-padrões do DOP. As indagações que iam além da estrita condição formal, problematizavam a própria finalidade do equipamento e a relação do usuário - cidadão com os equipamentos públicos do Estado.

Segundo o coordenador do Grupo de Planejamento do PAGE Plínio Sampaio, mesmo admitindo ser "um leigo" em arquitetura tendo como sua "roda particular" amigos arquitetos, de filiação moderna como Joaquim Guedes, Vilanova Artigas, Carlos Milan, entre outros, a abertura para o novo fazer arquitetônico era imperativa, pois, a adoção moderna era uma "lógica" dos novos tempos, um percurso natural. Para ele os profissionais envolvidos eram recém-formados e, portanto, adeptos as mudanças e críticas da prática de obras do Estado.

As propostas "modernas" compreenderam, o cuidado com as condições físicas locais e o uso de novas tecnologias, mas, sobretudo, a abertura para fluir a prática de uma nova visão arquitetônica que questionava os fundamentos teóricos e valores anteriores presentes nos edifícios públicos.

Esse "enlace" de renovações, possibilidades e expectativas animadas pelo "espírito desenvolvimentista da época", aliando a "modernização" do país à produção de edifícios públicos intensificados através do Plano de Ação, com o objetivo de "varrer o atraso do Estado", conheceu uma inflexão peculiar de procedimentos e estruturação, adicionando novos conceitos e principalmente incorporando a noção de Plano em grande escala. Condição necessária para viabilizar os projetos contratados pelo Estado, financiados com recursos do Instituto de Previdência do Estado de São Paulo - IPESP4 - e de Fundos especiais entre outros recursos.

A inserção de novas elaborações projetuais e construtivas aliadas a novas correntes de pensamento difundido pela intelectualidade, que se juntava ao governo através do PAGE, foram determinantes para as inovações nos edifícios públicos construídos na capital e no interior do Estado.

\section{O PAGE e os novos Fóruns de Justiça}

A arquitetura dos novos fóruns discutia entre outros aspectos, a publicização de seus espaços e a hierarquia espacial vigente, tendo no seu posto e no plano mais alto quais as necessidades e representações que a Justiça estabelecia como a ideal para ser reconhecida. Sobre essa questão comentou Fábio Penteado em relação ao estudo para o Fórum de Araras:

O que é um Fórum? Você pode pegar a história para enriquecer, aumentar o livro, história antiga, etc. Aívem a realidade se aproximando da realidade, onde ele é? Para quem que ele vai atender? Em Araras devia ter quinze mil habitantes. Também fui ver o que era um Fórum e tinha um padrão geral, assim era a descrição que vi na época: um padrão dentro daquela linha dos juízes, do comando não sabe da onde. Um prédio Vestusco. Eacomodava no terreno, conforme o projeto vinha uma escada, com pé direito duplo na entrada na porta, uma réplica de salas dos passos perdidos que as pessoas se dirigem. (...) (PENTEADO, 2007)

O arquiteto, na análise deste equipamento, observa que o Fórum não é, e não deve ser visto, de forma restrita aos serviços da justiça, mas sim deve atender, acima de tudo, as necessidades objetivas do cidadão comum. Este vai até o fórum a procura, principalmente, dos demais serviços lá oferecidos, tais como os cartoriais, por exemplo. ${ }^{5}$

O Fórum não é só Fórum de Justiça, ele tem lá o registro imobiliário, os cartórios, então o cidadão nasce um filho vai registrar, morreu alguém ele tem que fazer inventário. Ai entra todo o aspecto da realidade. (PENTEADO, 2007)

Ainda sob a condução desse campo de análise, Penteado, notando as relações cognitivas absorvidas através dos espaços construídos, constata que os cidadãos comuns estavam intimidados pela arquitetura forense recorrente, sua simbologia e o universo social que representava, e que por vezes, ainda representa.

O cidadão comum ao se aproximar já tem dúvida, já tem medo é ancestral. Na porta daquele prédio tem um cidadão que é guarda que pode barrá-lo e 


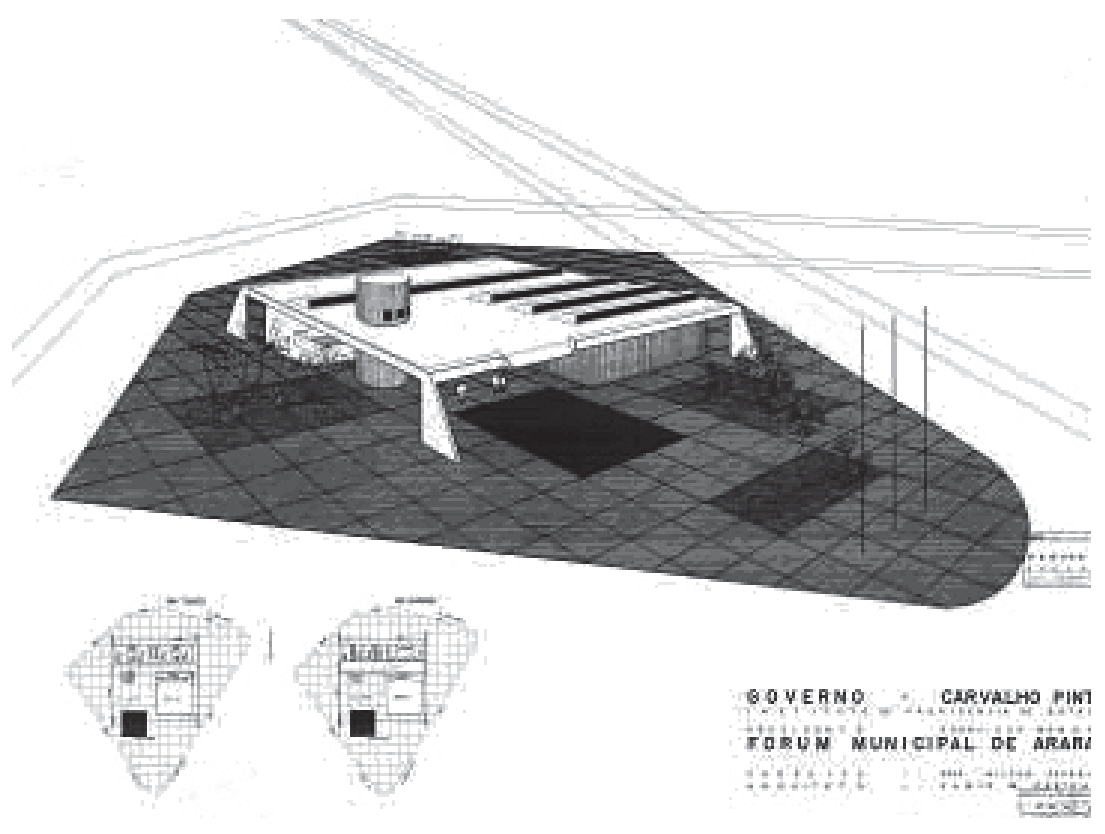

Figura 3: Perspectiva e plantas do Fórum de Araras. Fonte: arquivo da Companhia Paulista de Obras e Serviços.

Segundo o PAGE a principal função do Grupo era "estudar um Plano de Ação do Governo do Estado, acompanhar a execução do Plano e proceder a sua revisão anual, a fim de adequá-lo as mutações da conjuntura econômico-financeira e as decorrentes da própria execução e funcionamento das obras, serviços e empreendimentos". (PAGE, 1959, p.20)

A atuação do Grupo resultou entre outras ações no Decreto Estadual $n^{\circ} .34 .656$ de 12/ 02/1959, que regulamentava as atuações do próprio Grupo de Planejamento, com as normas para coordenação e planejamento dos serviços e obras do Estado; na Lei Estadual $n^{\circ} .5 .444$ de 17/11/1959 que regulamentava o caráter financeiro do Plano; na Lei $n^{\circ}$. 6.047, de 27 /01/ 1961, para assegurar a revisão anual do Plano e na Lei Estadual $n^{\circ} .5 .994$ de 30/12/1960, que estabelecia normas para exploração econômica da propriedade rural. Conforme o II Plano de Ação, elaborado ele pode não fazer nada, mas está lá relaxado, já maltratando pelo princípio de ser autoridade. (PENTEADO, 2007)

Conclui ainda o arquiteto, que ao romper essa concepção tradicional adotada para estes equipamentos, rompe-se também o "princípio de autoridade" e hierarquia em que ela se fundamentava, favorecendo uma real apropriação destes espaços pelo cidadão comum, para tanto propôs para o município de Araras:

(...) eu propus um Fórum que não tivesse porta. A área era uma praça grande, tinha espaço. Então a idéia em princípio foi de usar um espaço onde chamaria de Fórum, ele gerava uma sombra na pracinha onde o cidadão aguardava na sombra. (PENTEADO, 2007)

Em editorial no periódico Folha de São Paulo, Tendências e Debates, publicado em 16 de julho de 2007, "Chega de Excelências, senhores!" 6 o Promotor de Justiça do Distrito Federal Fausto Rodrigues de Lima, comenta um episódio em que o juiz cancelou uma audiência porque um trabalhador compareceu ao Fórum de chinelos, explica sobre o fausto dos edifícios da justiça: "(...) os palácios de mármore e vidro da Justiça, os altares erguidos nas salas de audiência para juízes e promotores e o tratamento 'Excelentíssimo' dispensado às altas autoridades são resquícios diretos da mal resolvida proclamação da República brasileira, que manteve privilégios monárquicos aos detentores do poder". Conclui o promotor que aos "nobres" foi mantido por lei tratamentos diferenciados e aos demais cidadãos thes coube a função de "súditos". Esses comentários, bastante atuais, conferem propriedade às observações e as concepções que o arquiteto Fábio Penteado e outros problematizaram e prepuseram para os edifícios da Justiça, durante as ações do PAGE, buscando "romper o princípio de autoridade" instituído, elaborando soluções arquitetônicas abertas a novos valores.

\section{Moderno e "modernizador": o caráter social dos Fóruns de Justiça}

O mesmo princípio para romper a hierarquia tradicional destes edifícios formulado para Araras, fazer do edifício forense uma praça coberta, também foi adotado por Paulo Mendes da Rocha, autor do projeto do Fórum de Avaré. Para o arquiteto, a importância do conforto e atendimento ao público, 

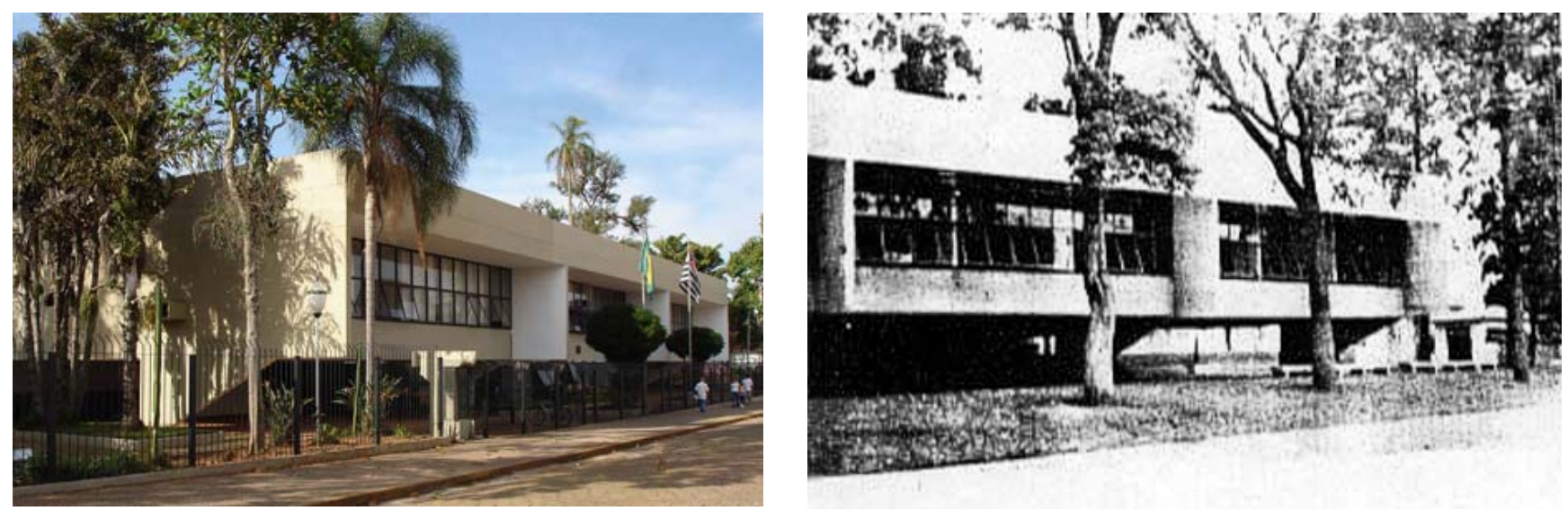

Figuras 4 e 5: Fórum de Avaré atualmente gradeado interferindo na fluência proposta pelo arquiteto Paulo Mendes da Rocha. Imagem na época de sua inauguração. Fonte da figura 4: foto da autora. Fonte da figura 5: revista Acrópole, 1961.

para o candidato à sucessão de Carvalho Pinto, José Bonifácio Coutinho Nogueira, seu Secretário de Agricultura que perderia as eleições para Adhemar de Barros Filho em 1962, na elaboração do I Plano de Ação participaram "todos os escalões dos serviços públicos e Assembléia Legislativa".

Subordinado ao Grupo de Planejamento estava a Equipe Técnica formada por especialistas que mediavam e coordenavam as ações e necessidades diretamente com as Secretarias. Integraram a Equipe Técnica do PAGE Celso Monteiro Lamparelli, Francisco Whitaker Ferreira, Mário Laranjeira de Mendonça, Domingos Theodoro de Azevedo Netto, Henrique Silveira de Almeida, Antonio Amílcar de Oliveira Lima, José Reinaldo Gomes, Pedro Penteado Nogueira.

4 Instituto de Previdência do Estado de São Paulo foi criado pela Constituição Paulista de 9 de julho de 1935, com a finalidade inicial de amparar o servidor público e seus dependentes. Como forma de que nem sempre iam aos fóruns para os serviços da justiça, estavam no topo das necessidades básicas de seus usuários.

As soluções arquitetônicas propostas, no período de produção do PAGE, guardam distintas modulações e concepções, apesar das formulações comuns presentes na arquitetura moderna, tais como a afirmação da verdade construtiva, a renovação do agenciamento espacial, a liberação da vedação do sistema tradicional construtivo, entre outros. A quebra da hierarquia nem sempre é interpretada na mesma condição e as necessidades básicas da justiça nem sempre contempladas. ${ }^{7}$

Foram realizadas através do PAGE aproximadamente quatrocentas novas construções projetadas por vários arquitetos modernos paulistas, ou exercendo a profissão no Estado, 8 mesmo de forma pontual, como aconteceu com Afonso Eduardo Reidy, um dos nomes paradigmáticos dos arquitetos do chamado "Grupo Carioca", 9 que projetou o edifício para o Fórum de Justiça do município de Piracicaba (1961).

Entre os edifícios executados para o Poder Judiciário podemos citar os Fóruns de Araras, de Fábio Penteado (1959); de Avaré, de Paulo Mendes da Rocha (1962); de Itapira, de Joaquim Guedes (1958); de Orlândia, de Jorge Wilheim (1961); de Promissão, de Vilanova Artigas (1959, o projeto e construção em 1969); de São José dos Campos, de Paulo Sérgio Souza Silva (1965?); de Rio Claro, de Carlos Gomes
Cardim e Luciano Gomes Cardim (1963); de Porto Feliz, de Alberto Botti e Marc Rubin (1963); e de Socorro, de David Libeskind, (1961). ${ }^{10}$

Como observado, a "produção forense IPESP" 11 apresentou diversificadas elaborações projetuais, mas, sobretudo emblematicamente, agenciou-se também entre boa parte dos profissionais uma comunhão de aspectos formais e de sentido social dos seus projetos. Seus agentes participaram do mesmo cenário cultural da produção arquitetônica do período, no qual a arquitetura moderna incluindo a desenvolvida em São Paulo procurava expressar e auxiliar a modernização do país. Isto não elimina diferenças, havia arquitetos que enfatizavam, no quadro de referências modernas, questões de materialidade e construtibilidade, como exemplo, Jorge Wilhein em Orlândia, Bratke em Amparo e Botti e Rubin em Porto feliz onde se destacam elementos de composição modular.

De forma geral, os edifícios contribuíram para o reforço simbólico da modernização que o Estado buscava imprimir em seus equipamentos públicos. A mudança explorada pelos arquitetos não foi a de qualquer transformação, mas daquela que buscava aliar modernização e democracia, rompendo, ou atuando contrariamente ao arcaísmo social.

De forma mais incisiva, na produção forense foi proposta, por alguns arquitetos, a "reinvenção do 

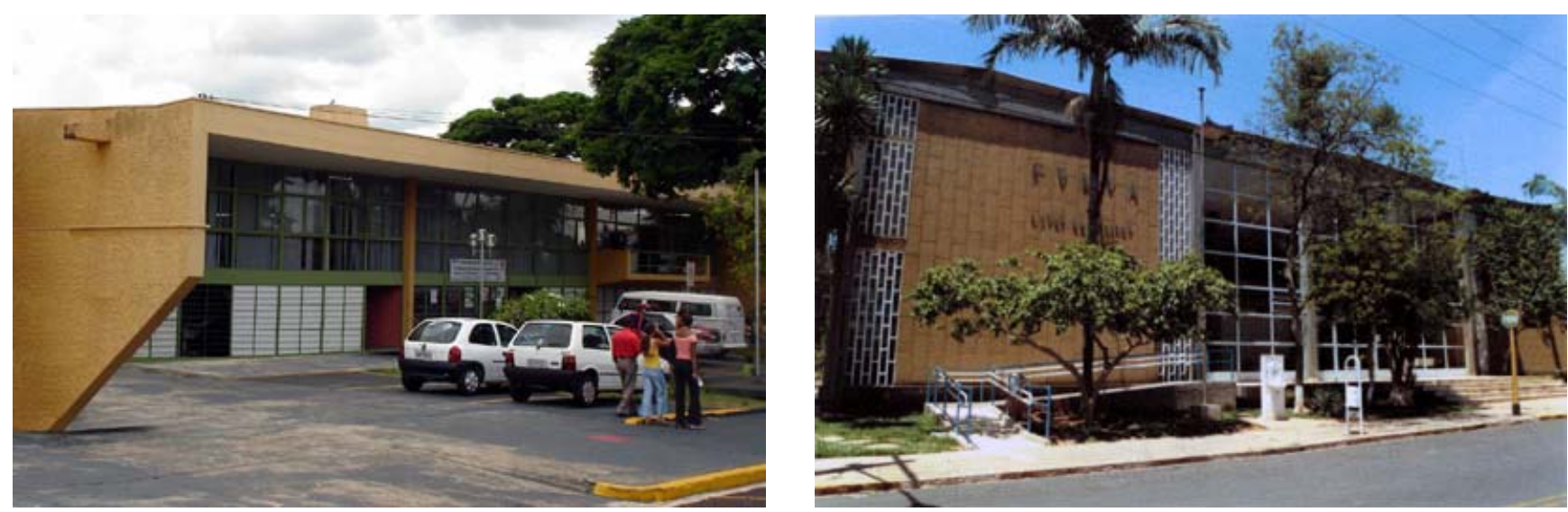

Figuras 6 e 7: Fórum de Orlândia de Jorge Wilhein e de Amparo de Oswaldo Bratke. Fonte: fotos da autora.

aplicação de seus recursos financeiros investiu em obras públicas para locação do Estado.

${ }^{5}$ Entrevista de Fábio Penteado ao Grupo de Pesquisa: Arte e Arquitetura, Brasil: diálogos da cidade moderna e contemporânea da EESCUSP em 09 de abril de 2007, disse Penteado: A minha formação aconteceu tudo por acaso, eu comecei como jornalista de arquitetura. Também saí do zero para editor da revista que era a mais importante na época. A revista Visão. Fui editor durante vários anos. Eu aprendi e convivi com gente muito boa do jornalismo. Em função dessa experiência o arquiteto reconhece na sua análise sobre o equipamento da justiça: eu fui visitar os fóruns, eu tinha uma visão jornalística, eu fui editor de arquitetura da revista Visão durante muito tempo. $\mathrm{O}$ arquiteto trabalhou no periódico mensal, Visão entre os anos de 1956 e 1962.

6 "Chega de Excelências, senhores!" Jornal Folha de São Paulo, $1^{\circ}$ Caderno, Coluna "Tendências e Debates", publicado em 16 de julho de 2007

7 Dentre as necessidades básicas ausentes nos diversos fóruns analisados estão:
Direito" 12, através da dissolução do forte simbolismo, presente na hierarquia espacial já apontada e na sua monumentalidade. Evidentemente, isso variava de arquiteto para arquiteto, ou dependia da sua filiação política a clareza da atitude. Mas o conjunto da produção reafirma o signo apontado.

A nova fase de produção através dos edifícios modernos viabilizados pelo PAGE possuiu um propósito mais complexo, envolvendo uma nova forma do saber e fazer arquitetura, percebida na introdução de novas tecnologias, conceitos e relações que se interagiam compondo um macrocosmo de questões. Ao propor um rompimento dos paradigmas adotados na produção forense anterior, essa produção estabeleceu uma nova simbologia, que de certa forma, expressava a modernização do Estado, percebida no conjunto dos aspectos espaciais, formais e sentidos sociais de seus projetos. Neste sentido, era uma produção que articulava a linguagem moderna com objetivos sociais.

\section{Conclusão}

Os edifícios modernos da justiça foram elaborados, como visto, por distintos arquitetos que embora participassem do mesmo cenário cultural, nem sempre conjugavam das mesmas preocupações sociais, do alcance, ou do lugar da arquitetura frente às questões socioculturais e dos princípios e interpretações do equipamento Fórum. Ou seja, há distintas maneiras de afrontar a história. Desse modo, em Artigas e Cascaldi em Promissão, Paulo Mendes em Avaré e Fábio penteado em Araras localizamos entendimentos espaciais críticos (destacando a "contra-concepção" tradicional dos Fóruns de Justiça); inversões hierárquicas recolocando espaços e acessos; espaços franqueados permitindo a correspondência entre o exterior e interior do edifício com interação e fluidez dos seus ambientes. Em Wilhein, Bratke, Botti e Rubin identificamos a tendência da padronização construtiva. Joaquim Guedes em Itapira emprega os novos materiais e as possibilidades construtivas (pilares delgados sustentando a grande laje de concreto) enfatizando o conjunto formal da obra. Ainda nesta ordem, privilegiando a expressividade do conjunto formal da obra, porém utilizando as formulações espaciais tradicionais dos edifícios da Justiça, incluem-se os fóruns de David Libeskind em Amparo e Reidy em Piracicaba.

Se há diferenças, vimos que também há convergências que emblematicamente agenciam entre elas um conjunto de aspectos formais e, em que pese propostas espaciais distintas, concorreram por atribuir um sentido social e cultural mais amplo e evidente, por exemplo, na publicização proposta para os Fóruns de Justiça evidenciados nas praças cobertas e no Salão do Júri extraído do corpo principal do edifício.

A arquitetura moderna pensava-se como um aparato ideológico de pedagogia social; a clareza de suas 

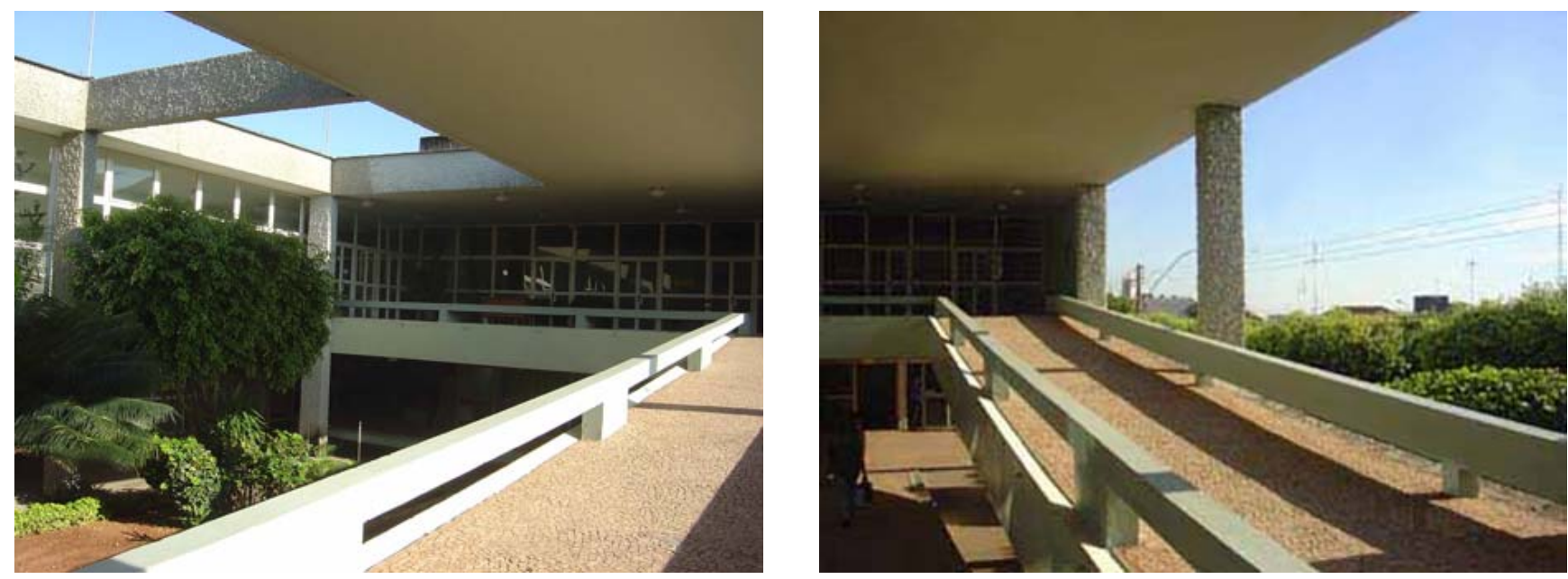

Figuras 8 e 9: Fórum de Promissão de Vilanova Artigas e Cascaldi. Detalhe das rampas de distribuição de acesso que substitui o átrio "Passos Perdidos", que antecede o Salão do Júri. A rampa dilui a unidirecionalidade dessa condução e ainda auxilia na comunicabilidade e transposição entre o interior e exterior do edifício, que se organiza contornando um grande jardim interno. O júri está no pavimento superior dentro do corpo principal do edifício. Não é uma praça coberta, mas sim um confortável ambiente agregando jardim e espaços franqueados. Fonte: fotos da autora.

separação adequada para defesa e acusação e acesso distinto para o réu.

${ }^{8}$ Este número ainda é parcial, mas se refere exclusivamente ao conjunto dos novos equipamentos - fórum, escolas, postos de saúde, etc.- Não abrange o total de obras, que inclui as reformas. Somadas ambas as tipologias o número de obras é superior a mil.

${ }^{9}$ A denominação "grupo carioca" ou "escola carioca" é imprecisa, mas é utilizada aqui para caracterizar a arquitetura moderna produzida no Rio de Janeiro a partir da atuação de Lúcio Costa, tanto na Escola Nacional de Belas Artes, como no projeto do Mi- formas e ambientes deveria revelar e levar ao exercício de formas mais elaboradas (superiores) de convívio e sociabilidade (próprios de uma condição social progressista). Guardada a dimensão do pensamento do arquiteto Fábio Penteado a "reinvenção do direito", percebe-se que ele sintetiza o desejo de um grupo de arquitetos de sua geração, o de "reformular a sociedade através da arquitetura".

Em que pese os objetivos sociais, as obras modernas sofreram resistências e críticas. De qualquer modo, a condição atual da sociedade não escapou da leitura de um dos protagonistas do modernismo e atuante nesta produção específica. Assim, as questões sociais que a arquitetura trabalhou em projeto, não podem mais ser contemplada apenas pelos projetos, como o próprio Artigas declarou ao final de sua vida:

Sou de uma geração que procurou soluções para todos os problemas. No meu tempo, era possível ser meio enciclopedista, entregar-se individualmente à tarefa de pensar nestas questões. Podem ter me condenado. Me chamaram de sonhador, de comunista, mas foi nisso que gastei os melhores anos de minha vida. Sei que fiz uma poesia desse processo todo. Fiz uma imensa poética. Dos primeiros aos últimos versos. Tenho orgulho tão grande do meu passado, das minhas ilusões, de realizar essa pequena obra, me sinto tão muito bem. Duro seria se não tivesse nada para dizer e chegasse nessa hora ainda esperando uma oportunidade. É um papel cumprido integralmente.

O que me impressiona é que os problemas que nos restaram têm, hoje, uma escala que já está muito longe da minha capacidade individual de interpretá-los. Estarei fora de poder opinar sobre isso. Acredito que já estarei participando do Cosmo de uma maneira bem diferente. (ARTIGAS, 1997, p. 33)

A história de concepção e de vida dos Fóruns de extração moderna parece corroborar a formulação de Artigas. Os problemas da sociedade contemporânea, para o bem ou para o mal, parecem exigir uma nova interpretação do lugar da arquitetura e do arquiteto na sociedade, e do alcance de sua autoridade social para respondê-los.

Os Fóruns do Estado de São Paulo, no período de sua concepção, contribuíram para uma expressão simbólica de modernização do Estado, associada ao PAGE e a outras ações, agregaram-se ainda, de forma paradigmática, à construção de Brasília e às esperanças sociais que o governo JK estimulou ${ }^{13}$. No entanto, ainda que haja uma representação do Estado que se quer moderno, empreendedor e progressista, há outra em direção oposta, que se faz presente no ritual da Justiça, sendo que, na busca de implementar novos eixos operativos através 

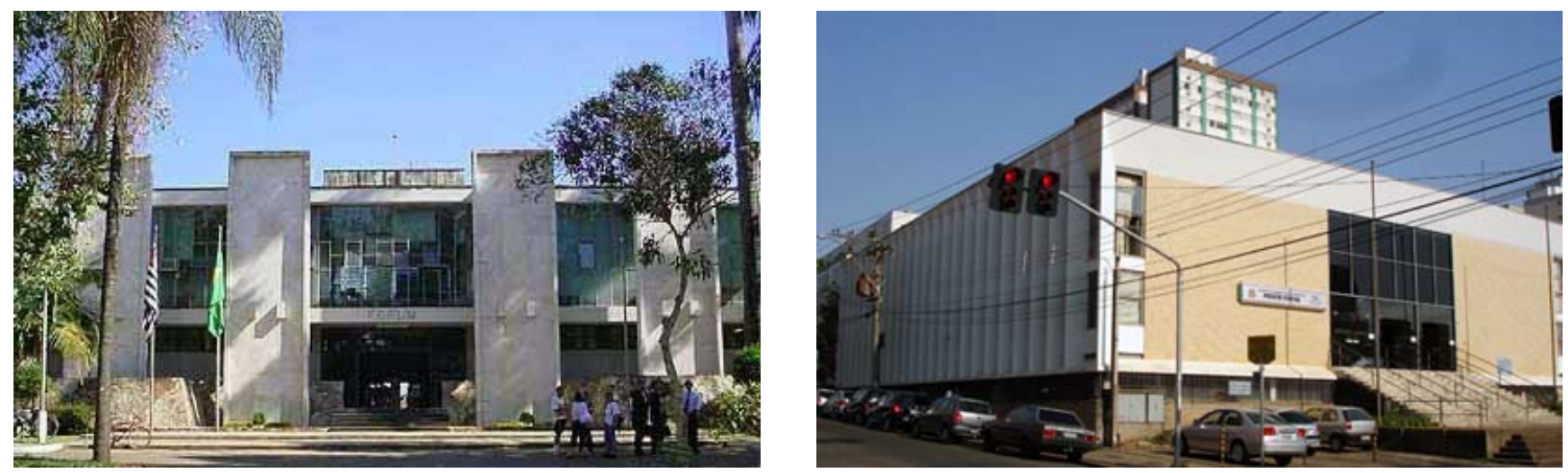

Figura 10: Fórum de Socorro, de David Libeskind. Fonte: foto da autora.

Figura 11: Fórum de Piracicaba, de Affonso Eduardo Reidy. Fonte: foto da autora.

nistério da Educação e Saúde Pública, ainda que Reidy não tenha participado do projeto do MESP.

10 Ver: PENTEADO, Fábio. Fábio Penteado: ensaio de Arquitetura / Fábio Penteado, São Paulo, Empresa das Artes, 1998, p.56.

${ }^{11}$ Classificação adotada para diferenciar esta produção elaborada pelos arquitetos e engenheiros funcionários do DOP, que ainda durante os anos cinqüenta e sessenta construíam edifícios padrões. Ainda que muito ampliada no Governo Carvalho Pinto, em levantamentos nos arquivos do Cia Paulista de Obras e serviços - CPOS e IPESP, foi constatado que a prática do Governo do Estado utilizar recursos do IPESP na construção de edifícios públicos já existia na gestão anterior de Jânio Quadros (01/1955 01/1959).

${ }^{12}$ A "reinvenção do Direito" foi reafirmada pelo arquiteto Fábio Penteado, em ocasião de sua homenagem no III Seminário DOCOMOMO São Paulo, ocorrido em 2005 e em entrevista em 2006.

13 Partes das obras do PAGE foram concluídas já nos conturbados anos de Jânio de apropriações e percepções movidas pelos novos conceitos arquitetônicos, estas representações nem sempre foram rompidas.

O cerimonial quase ritualístico que persiste até hoje, objeto de discussão também pelos juristas, indica uma dessas permanências. O uso da beca, mas não só ela, o representa de forma clara. ${ }^{14}$

Dentro dessa perspectiva, o rompimento de certos paradigmas arquitetônicos, como a ausência da referência ao neoclássicos ou acadêmico abarca uma curiosa ambigüidade, por um lado o limite das inovações apontando para uma justiça republicana democratizada e por outro, coincidindo com novos ritos jurídicos.

Iconograficamente e materialmente, a simbologia foi elaborada com uma linguagem moderna, de certa forma estilizada, como nos quatro pilares principais de Araras, cujos aspectos formais remetem a uma balança, e nos azulejos de Mário Gruber, no mesmo edifício, cuja estampa é de uma balança em formato geométrico, ou no Fórum de Itapira, onde seu júri é trabalhado de maneira cenográfica, com iluminações zenitais e jogos das lajes.

A extinção do simbolismo tradicional em prol de uma nova simbologia que expressasse modernização, e a própria modernidade, entendida como uma condição social progressista, leva a refletir sobre a pertinência da simbologia adotada até a atualidade. Há, talvez um sentimento de que os edifícios de extração acadêmica expressassem o contrário dos objetivos republicanos, em vez de "Igualdade, Liberdade e Fraternidade" teríamos a afirmação de uma hierarquia social rígida irmanada à espacial. A continuidade e a franquia espacial dos novos Fóruns viria a transfigurar essa harmonia em prol da Instituição facultando os valores da modernidade.

Estes novos espaços do judiciário alinharam um pensamento reformulador com ideais pedagógicos (educar o homem para participação social) ao recolocar o cidadão comum ante o uso e apropriação dos equipamentos públicos, ainda que isto, permanecesse como um desafio para as novas culturas arquitetônicas. Esta produção revela-nos que a representação do país, ainda que no âmbito regional do estado de São Paulo também esteve associada a novas formas de relações sociais, de espaços democráticos ainda que compatibilizada com as expectativas do "Estado modernizador" e "anos de euforia" na qual a arquitetura no país viveu um momento singular de produção. Reitera e expõe para as novas culturas o desafio que a arquitetura assume ante um novo lugar despido de autoridade, integrando o homem, espaço e sociedade.

Em que pese as permanências da liturgia do judiciário, que como evidencia o Promotor de Justiça do Distrito Federal Fausto Rodrigues de Lima, pode ser utilizada para reafirmar privilégios e não afirmar a igualdade e impessoalidade públicas, e as 

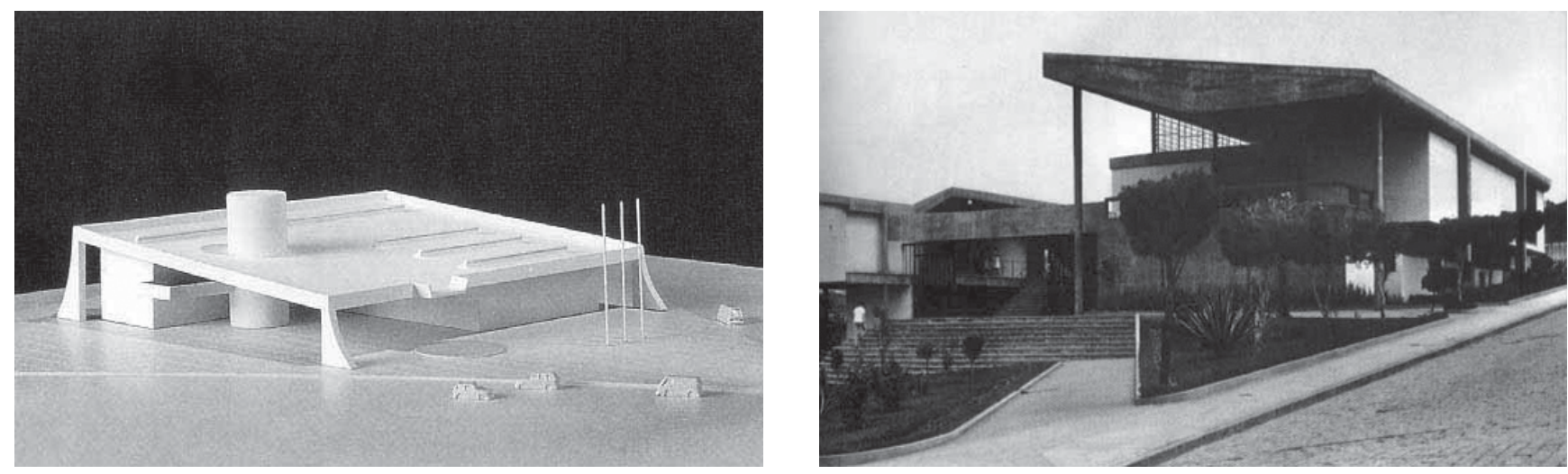

Figura 12 : Maquete do Fórum de Araras. Fonte: PENTEADO, 1998.

Figura 13: Fórum de Itapira. Fonte: CAMARGO, 2000.

Quadros e João Goulart. Portanto, ainda que sem a égide dessa "comoção nacional progressista" dos anos JK, compactuavam da mesma fórmula de incentivo.

${ }^{14}$ Há no rito uma simbologia muito forte, o qual Rossi associa ao mito e também ao monumento. Para Rossi, "a importância do rito e sua natureza coletiva, seu caráter de elemento conservador do mito, constituem uma chave para a compreensão do valor dos monumentose, para nós, do valor da fundação da cidade e da transmissão das idéias na realidade urbana". (ROSSI, 1998, 2ª ed. p. 7). Apesar de Rossi estar se referindo à igreja e ao rito religioso, não é despropositado pensar o rito jurídico sendo possibilitado pelo monumento que abriga o judiciário, particularmente, se pensarmos no Palácio da Justiça. Nesta lógica, a mudança da arquitetura do "monumento" possibilitaria, ou permitiria, um rito distinto e democrático. Dentro dessa perspectiva, há o rompimento de certos paradigmas, como a ausência da referência aos modelos neoclássicos ou acadêmicos, como também dos sím- limitações do alcance das propostas modernas efetuadas, que podem ser traduzidas nas palavras de Artigas, "os problemas que nos restaram têm hoje uma escala que já está muito longe da minha capacidade individual de interpretá-los" (ARTIGAS, LIRA (org) 2004,p.180), o legado da produção do PAGE guarda um vigor que auxilia a repensar a própria disciplina arquitetônica .

\section{Referências bibliográficas}

ARGAN, Giulio Carlo. História da Arte como História da Cidade. São Paulo: Martins Fontes, 1993.

ARTIGAS, Rosa; LIRA, José Tavares Correia de, (org.), Caminhos da Arquitetura, São Paulo: COSACNAIF, 2204.

BALTY, Jean Ch. Curia Ordinis, Recherches d'architecture et d'urbanisme antiques sue les curies provincials du monde romain, Impression Palais des Académies de L'université livre de Bruxelles, 1983.

BANDECCHI, Brasil. Elementos de História do Direito Brasileiro, Ed. Pannartz, São Paulo, 1984, $2^{\text {a Ed. }}$

BUZZAR, Miguel Antonio. João Batista Vilanova Artigas, elementos para uma compreensão de um caminho da arquitetura brasileira, 19381967. Dissertação de Mestrado, São Paulo: FAUUSP, 1996. Orientação Prf. Dr. Paulo Valentino Bruna.

CAMARGO, Mônica Junqueira. Joaquim Guedes, São Paulo: Cosac \& Naify, 2000.

CHAUÍ, Marilena de Souza. Cultura e Democracia: O discurso competente e outras falas, São Paulo: Ed. Moderna, 1981.
CORDIDO, Maria Tereza Regina Leme de Barros, ,Arquitetura forense do Estado de São Paulo produção moderna, antecedentes, e significados. Dissertação EESC-USP, 2007.

COSTA, Emília Viotti da. O Supremo Tribunal Federal e a Construção da Cidadania. 1. ed. São Paulo: Instituto dos Estudos Jurídicos e Econômicos, 2001.

FRAMPTON, Kennet. História Crítica da Arquitetura Moderna. São Paulo: Martins Fontes, 1997, 1. ed

JACOB, Robert. La formazione storica dell' architettura giudiziaria. In: Zodiac, $\mathrm{n}^{\circ} 14$, Itália, setembro de 1995, p. 30

LÉVAY, Emeric. O Palácio da Justiça: marco cívico-cultural no coração de São Paulo. São Paulo: Monografia, s/d

MARTINS, Carlos F. Arquitetura e Estado no Brasil Elementos para uma Investigação sobre a Constituição do Discurso Moderno no Brasil; a Obra de Lúcio Costa (1924/1952). Dissertação de Mestrado, FFLCH/USP, 1987, mimeo.

PENTEADO, Fábio, Fábio Penteado: ensaio de Arquitetura / Fábio Penteado, São Paulo, Empresa das Artes, 1998.

ROCHA, Paulo Mendes da. Mendes da Rocha. Lisboa: Ed. Blau, 1996.

\section{PAGE}

PINTO, Carvalho, Plano de Ação do Governo, São Paulo: Imprensa Oficial . 1959

Mensagem apresentada pelo Governador Carvalho Pinto à Assembléia Legislativa do Estado de São Paulo. São Paulo: Imprensa Oficial, 1960. 
bolos tradicionais adotados pela justiça, havendo, da mesma maneira, a modernização daqueles paradigmas na produção do século XX, o que caracteriza uma curiosa ambigüidade: por outro lado, o limite das inovações, pois inovar a Justiça não significa eliminá-la e nem reconhecer o seu passado, a inovação sempre aponta para a democratização, para uma Justiça Republicana, digamos radical. Desse modo, a simbologia da Justiça se faz presente, coincidindo com a possibilidade de um novo rito jurídico.
Mensagem apresentada pelo Governador Carvalho Pinto à Assembléia Legislativa do Estado de São Paulo - 14 de março de 1961, para a Lei $n^{\circ}$ 6.047, de 27 de janeiro de 1961, São Paulo, Decretos e Relatórios. Imprensa Oficial. s/d.

Exposição do Governador Carvalho Pinto para a $4^{a}$ reunião de governadores com o excelentíssimo Presidente da República, São Paulo: Imprensa Oficial, 1961.

\section{Leis e Decretos}

ESTADO DE SÃO PAULO. Coleção das Leis e Decretos 1889/1891. 2a ed. Edição oficial. São Paulo: Imprensa Oficial do Estado de São Paulo.

Coleção das Leis e Decretos 1952. Edição oficial. São Paulo: Imprensa Oficial do Estado de São Paulo.

Coleção das Leis e Decretos1966. Edição oficial. São Paulo: Imprensa Oficial do Estado de São Paulo.

Coleção das Leis e Decretos 1975/1980. Edição oficial. São Paulo: Imprensa Oficial do Estado de São Paulo.

Perfil da Administração Pública. 1966. Edição oficial. São Paulo: Imprensa Oficial do Estado de São Paulo.

Perfil da Administração Pública. 1990. Edição oficial. São Paulo: Imprensa Oficial do Estado de São Paulo.

Entrevistas realizadas pelo Grupo de Pesquisa

"Arte e Arquitetura, Brasil - diálogos na

cidade moderna e contemporânea" (ArtArqBr)

SAMPAIO, Plínio de Arruda - 05/03/2007 - Grupo de Pesquisa "Arte e Arquitetura, Brasil - diálogos na cidade moderna e contemporânea" (ArtArqBr) Camila Venanzi, Lucia Noemia Simoni, Maria Tereza R. L. B. Cordido e Miguel Antonio Buzzar.

CASTALDI, Ivan Gilberto - 09/03/2007- Grupo de Pesquisa "Arte e Arquitetura, Brasil - diálogos na cidade moderna e contemporânea" (ArtArqBr) Lucia Noemia Simoni, Maria Tereza R. L. B. Cordido e Miguel Antonio Buzzar.

LAMPARELLI, Celso Monteiro -02/04/2007- Grupo de Pesquisa "Arte e Arquitetura, Brasil - diálogos na cidade moderna e contemporânea" (ArtArqBr) Lucia Noemia Simoni, Maria Tereza R. L. B. Cordido e Miguel Antonio Buzzar.

VACCARI, Marcolino e PASSOS, Maria Lúcia de Brito 26/03/2007

Fábio Moura Penteado - 09/04/2007 - Grupo de Pesquisa "Arte e Arquitetura, Brasil - diálogos na cidade moderna e contemporânea" (ArtArqBr) Maria Tereza R. L. B. Cordido e Miguel A. Buzzar.
FERREIRA, Francisco Whitaker- 16/04/2007 - Grupo de Pesquisa "Arte e Arquitetura, Brasil - diálogos na cidade moderna e contemporânea" (ArtArqBr) Maria Tereza R. L. B. Cordido.

\section{Periódicos}

Acrópole. São Paulo: Ed. Gruenwald Ltda, nº 209. São Paulo: Ed. Gruenwald Ltda, n² 256; 1960. São Paulo: Ed. Gruenwald Ltda, n² 257; 1960. São Paulo: Ed. Gruenwald Ltda, n²73; 1961 São Paulo: Ed. Gruenwald Ltda, n² 292; 1963. São Paulo: Ed. Gruenwald Ltda, n 315; 1965 São Paulo: Ed. Gruenwald Ltda, n 320; 1965 São Paulo: Ed. Gruenwald Ltda, n 324; 1965. São Paulo: Ed. Gruenwald Ltda, n 342; 1965. $19 \overline{7}$. São Paulo: Ed. Gruenwald Ltda, n³77;

Arquitetura. Guanabara: Ed. Artenova Ltda, n³0, 1964.

Arquitetura e Urbanismo, $\mathrm{n}^{\circ} 43$.

HABITAT . São Paulo: Editora Habitat Ltda, n 4, 1951 São Paulo: Editora Habitat Ltda, n 63.

Jornal O Estado de S. Paulo. "Existe uma resistência cultural muito grande na própria Justiça". 18.5.2003.

Jornal Folha de S. Paulo. "PCC lança bomba no Fórum de Osasco". 16.3.2002.

"Justiça sofre $6^{\circ}$ atentado".19.3.2002.

"Medo avalia abuso policial e gera 'elite exterminadora'". 23.2.2004

Gullar, Ferreira. A turma da casa de Mário. Caderno llustrada, 16.1.2005, p. E12.

Rocha, João Cezar de Castro. Os profissionais da nacionalidade. Caderno Mais, $n^{\circ} 672$, de 16/01/2005

Lima, Fausto Rodrigues de, Chega de Excelências, senhores!, $1^{\circ}$ Caderno, Coluna "Tendências e Debates", 16 /06/ 2007

Revista da Directoria de Engenharia, Rio de Janeiro, maio, 1936.

ZODIAC n 14, Itália, setembro de 1995. 


\title{
Abstracts
}

\section{Edifícios públicos. Arquitetura forense: arquitetura moderna questionando a simbologia e mitos do Poder Judiciário no Estado de São Paulo}

\author{
Maria Tereza R. Leme de Barros Cordido
}

\begin{abstract}
In the State of São Paulo, forensic buildings as well as all other public buildings built until the end of the fifties were projected by the Department of Public Works (Departamento de Obras Públicas - DOP). Courts had an eclectic language, with strong academic ascendance, underlining the presence of the State and reinforcing its social hierarchy. By introducing a government plan with modernizing ideals the Action Plan (PAGE), by Carvalho Pinto (1959-1963) -, young architects found a soil to cultivate their ideas of a new architecture, in which forensic buildings were recomposed associating new forms of social relations and democratic spaces, even though they were suited to the expectations of a "modernizing State" and "years of euphoria". During this time, the national architecture has gone through an unique production and also contributed to divulge modern architecture.
\end{abstract}

Keywords: public buildings, action plan PAGE, forensic architecture. 